Classification

Physics Abstracts

$61.30 \mathrm{E}-64.70 \mathrm{M}$

\title{
A smectic A polymorphism at low temperature
}

\author{
G. Sigaud, M. F. Achard, F. Hardouin and H. Gasparoux \\ Centre de Recherche Paul Pascal, Domaine Universitaire, \\ Université Bordeaux I, 33405 Talence Cedex, France
}

(Reçu le 13 décembre 1984, accepté le 5 février 1985)

\begin{abstract}
Résumé. - Nous révélons pour la première fois à basse température un polymorphisme de phases smectiques $\mathrm{A}$ dans des mélanges de cyanocyclohexylcyclohexane et d'aminopyrène. Nous discutons brièvement les conditions d'apparition de phases smectiques fluides et bicouches dans ces nouveaux systèmes molécules aminées-molécules cyanées en association.
\end{abstract}

\begin{abstract}
Evidence is given for the first time at low temperature of an example of a polymorphism of smectic A phases, in mixtures of cyanocyclohexylcyclohexane with aminopyrene. We briefly discuss the conditions required to stabilize bilayered fluid smectics in such new cyano-amino associated systems.
\end{abstract}

\section{Introduction.}

Some years ago we described the unusual behaviour of mixtures of nonmesogenic polyaromatic amino compounds and cyanobiphenyls $(n C B$ or $n \mathrm{OCB})$ [1]. This was also noticed by other authors $[2,3]$. We recall that, the nematic and the smectic A phases of the polar mesogen (i.e. $8 \mathrm{OCB}$ ) are not destabilized by addition of rather large quantities of amino compounds although these solutes are often far from rod-shaped. To interpret these results the formation of weak donoracceptor complexes could be suggested by the occurrence and the stabilization of a smectic phase in mixtures of Schiff's bases nematogens and cyano compounds [4-6].

Moreover it is useful to recall that a partially bilayered arrangement of the $S_{A}$ phase has been evidenced in the cyanobiphenyls [7]. From this point of view it is surprising that the alkyl-cyanocyclohexylcyclohexane $(\mathrm{CCH} n)$ do not present any smectic A phase.

In the following we describe a very new peculiar amino-cyano binary system which shows that these homocyclic compounds can develop a smectic A polymorphism $\left(\mathbf{S}_{\mathbf{A}_{1}}, \mathbf{S}_{\tilde{\mathrm{A}}}, \mathbf{S}_{\mathbf{A}_{2}}\right)$ so far only obtained with long (three aromatic rings) polar rods [8].

\section{Experimental results.}

2.1. - Different binary systems of cyanobicyclohexyls and aminosubstituted polyaromatic molecules have been investigated (the various families of phase diagrams will be published elsewhere), but for this Letter we have selected one which we consider to be the most representative 


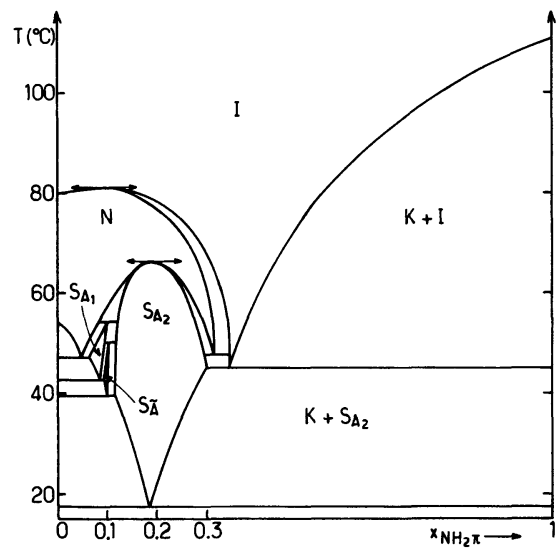

Fig. 1. - Isobaric $(x, T)$ phase diagram $(P=1 \mathrm{~atm}$.) for the system $\mathrm{CCH} 4$ (left), aminopyren (right).

of the unusual behaviour of these mixtures : the isobaric $(P=1 \mathrm{~atm}).(x, T)$ phase diagram of 4-cyanocyclohexyl-4'-butylcyclohexane $(\mathrm{CCH} 4)$ with 1-aminopyrene $\left(« \mathrm{NH}_{2} \pi »\right)$ (Fig. 1) :

- $\mathrm{CCH} 4$ is nematic from $55^{\circ} \mathrm{C}$ to $79{ }^{\circ} \mathrm{C}$ and presents a monotropic smectic $\mathrm{B}$ phase below $53^{\circ} \mathrm{C}$ which does not appear in the phase diagram which takes only the enantiotropic transitions (i.e. observed on heating) into account

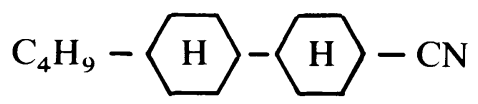

- $\mathrm{NH}_{2} \pi$ melts directly to an isotropic liquid at $115^{\circ} \mathrm{C}$

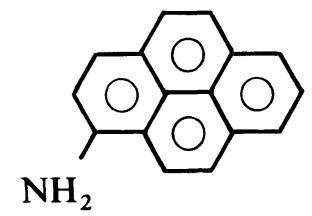

2.2. - The part of the phase diagram which involves the liquid crystalline phases has been established by optical polarizing microscopy and Differential Scanning Calorimetry (DSC) analyses of mixtures with increasing molar fractions of $\mathrm{NH}_{2} \pi$. The different induced smectic phases have been characterized by X-ray scattering. This enlarged part is reproduced in figure 2.

\section{Discussion.}

3. 1. - Several facts make this diagram very unusual :

i) Although a demixtion occurs above room temperature beyond $x_{\mathrm{NH}_{2} \pi}=0.2$ (solid aminopyrene precipitates when the temperature decreases), this amino compound presents an unusual solubility in the $\mathrm{CCH} 4$ solvent which was not anticipated for such an aromatic plate like solute.

ii) Despite the strong difference of shape between the two components, the nematic phase is slightly stabilized for $x_{\mathrm{NH}_{2} \pi}<0.08$ (Fig. 1). This is completely different from the fall in temperature which is observed by mixing a discotic with a rodlike mesogen [9]. 


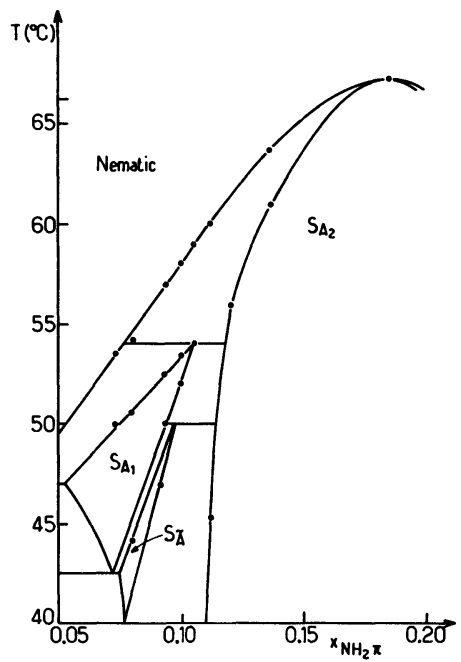

Fig. 2. - Part of the phase diagram for $0.05<x_{\mathrm{NH}_{2} \pi}<0.20$. Note the three smectic domains.

iii) The extension of the smectic domain raises with increasing values of $x_{\mathrm{NH}_{2} \pi}$ which deserves a detailed description.

The X-ray and DSC studies have shown that three kinds of fluid smectics (i.e. : the short-range order is liquid-like within the layers) exist in this domain : with increasing $x_{\mathbf{N H}_{2} \pi}$, a monolayer smectic $A\left(S_{A_{1}}\right)$ and a narrow fluid smectic antiphase $\left(S_{\tilde{A}}\right)$ precede the occurrence of a large domain of bilayer smectic $\left(S_{A_{2}}\right)$ according to the description of the different smectic $A$ phases of three phenyl ring polar molecules [8].

In relation to the X-ray patterns on powdered samples, the $S_{A_{1}}$ is characterized by only one sharp inner ring $\left(x=0.07, T=45^{\circ} \mathrm{C}, d_{001}=14.30 \AA\right)$. The $\mathrm{S}_{\mathrm{A}_{2}}$ phase corresponds to two commensurate sharp inner rings with similar intensities $\left(x=0.18, T=45^{\circ} \mathrm{C}, d_{001}=30.10 \AA\right.$, $d_{002}=15.05 \AA$ ). The intermediate $\mathrm{S}_{\tilde{\mathrm{A}}}$ phase presents two incommensurate sharp inner rings, indexed from additional measurements on single domains, as the 101 and 002 Bragg spots of an antiphase structure $\left(x=0.09, T=45^{\circ} \mathrm{C}, d_{101}=26.63 \AA, d_{002}=14.17 \AA\right)$.

The chief point is that this phase diagram provides the first evidence of a smectic A polymorphism obtained with short polar molecules (only two cyclohexyl rings in the rigid core). Such anomalies of periodicity have been reported by Brownsey et al. [10] in the ordered smectic B phase of $\mathrm{CCH} 5$ for which the structure is bilayered with local modulations of antiphase type. Thus, the bilayer smectic tendency is underlying in the pure bicyclohexyls but a fluid smectic has never been observed to date with these compounds and special requirements seem necessary in the lamellar structure to break the hexagonal tridimensional array of the $S_{B}$ phase (which exists as a slightly monotropic phase in the case of $\mathrm{CCH} 4$ ).

3.2. - Our preliminary studies varying the compounds mixed with the CCH4 only allow some speculations to be made concerning the reasons for which smectic A phases and especially the $\mathrm{S}_{\mathrm{A}_{2}}$ are stabilized in our system :

- First, a $\pi$ electron donating molecule (i.e. : an amino substituted compound) is necessary to obtain this behaviour. Thus the donor-acceptor complexation, which is likely to take place in this case, appears to play a prominent role. Moreover one can note that a $1 \mathrm{NH}_{2} \pi$ to $4 \mathrm{CCH} 4$ ratio seems the most favourable conditions for stabilizing the $\mathrm{S}_{\mathrm{A}_{2}}$ structure. Although a formation of a weak complex has been assumed for a long time in mixtures of this type [2], its analysis has 
hardly been made. But we point out that U.V. visible and fluorescence experiments are made easier in our mixtures due to another of their special properties : the $\mathrm{CCH} 4$ is a non-absorbing compound in the near U.V. as well as in the visible light and this allows us to follow the evolution of the system through the $\mathrm{NH}_{2} \pi$ alone (which, for example, itself plays the role of a fluorescent probe). We are presently performing this study.

- Second, the complexing ability of the solute does not seem to be the single relevant parameter : its size is also of great importance to induce the smectic $A_{2}$ phase. Thus steric interactions must be considered together with a donor-acceptor process. Additional studies are also necessary to precise how a rather large quantity of plate-like $\mathrm{NH}_{2} \pi$ is positioned in a bilayered structure of $\mathrm{CCH} 4$ molecules.

3.3. - Finally, we indicate that among the different chemicals which could replace the $\mathrm{NH}_{2} \pi$, are some red dyes and we think that it is possible to exploit this fact in two ways :

1) by studying the dynamics in these bilayered structures via optical experiments using green laser beams ;

2) by testing if these peculiar interactions change the order parameter of the dye in the liquid crystalline medium (we recall that $\mathrm{CCH} 4$ or its homologs are widely used in eutectic mixtures for displays).

\section{Conclusion.}

The main interest of these binary systems is, of course, that they provide a first way of obtaining at low temperature a polymorphism of smectics A. In addition they could become useful tools for studies in various domains, such as fluorescence [11], which has not yet been very much developed.

\section{Acknowledgments.}

It is a pleasure to thank Dr. A. M. Levelut for her help with the X-ray experiments on single domains.

\section{References}

[1] Sigaud, G., Achard, M. F., Hardouin, F., Gasparoux, H., Chem. Phys. Lett. 48 (1977) 122.

[2] Park, J. W., Labes, M. M., Mol. Cryst. Liq. Cryst. (Lett.) 34 (1977) 147.

[3] MacMillan, J. M., Labes, M. M., Mol. Cryst. Liq. Cryst. (Lett.) 56 (1979) 7.

[4] Park, J. W., BaK, C. S., Labes, M. M., J. Am. Chem. Soc. 97 (1975) 4398.

[5] ОН, C. S., Mol. Cryst. Liq. Cryst. 42 (1977) 1.

[6] Szabon, J., Janossy, I., Adv. Liq. Cryst. Res. Appl. Ed. L. Bata (Pergamon Press, Oxford-Akadémiai Kiado, Budapest) 1980, p. 229.

[7] Lydon, J. E., Coakley, C. J., J. Physique Colloq. 36 (1975) C1-45.

[8] Hardouin, F., Levelut, A. M., Achard, M. F., Sigaud, G., J. Chim. Phys. 80 (1983) 53 and the references therein.

[9] Hardouin, F., Sigaud, G., Achard, M. F., Gasparoux, H., Mol. Cryst. Liq. Cryst. 58 (1980) 155.

[10] Brownsey, G. J., Leadbetter, A. J., J. Physique Lett. 42 (1981) L-135.

[11] Subramanian, R., Patterson, L. K., Levanon, H., Chem. Phys. Lett. 93 (1982) 578. 